Ferrata Storti Foundation

\title{
Immune cell constitution in the tumor microenvironment predicts the outcome in diffuse large B-cell lymphoma
}

\author{
Matias Autio, ${ }^{1,2,3^{*}}$ Suvi-Katri Leivonen, ${ }^{1,2,3^{*}}$ Oscar Brück, ${ }^{3,4,5}$ Satu Mustjoki, ${ }^{3,4,5}$ \\ Judit Mészáros Jørgensen, ${ }^{6}$ Marja-Liisa Karjalainen-Lindsberg, ${ }^{7}$ \\ Klaus Beiske, ${ }^{8}$ Harald Holte, ${ }^{9}$ Teijo Pellinen ${ }^{10}$ and Sirpa Leppä ${ }^{1,2,3}$
}

${ }^{1}$ Applied Tumor Genomics Research Program, Faculty of Medicine, University of Helsinki, Helsinki, Finland; ' 2 Department of Oncology, Helsinki University Hospital Comprehensive Cancer Center, Helsinki, Finland; ${ }^{3}$ iCAN Digital Precision Cancer Medicine Flagship, Helsinki, Finland; ${ }^{4}$ Translational Immunology Research Program and Department of Clinical Chemistry and Hematology, University of Helsinki, Helsinki, Finland; ${ }^{5}$ Hematology Research Unit Helsinki, Helsinki University Hospital Comprehensive Cancer Center, Helsinki, Finland; ${ }^{6}$ Department of Hematology, Aarhus University Hospital, Aarhus, Denmark; ${ }^{7}$ Department of Pathology, Helsinki University Hospital, Helsinki, Finland; ${ }^{8}$ Department of Pathology, Oslo University Hospital, Oslo, Norway; ${ }^{9}$ Department of Oncology, and KG Jebsen Centre for B Cell Malignancies, Oslo University Hospital, Oslo, Norway and ${ }^{10}$ Institute for Molecular Medicine Finland (FIMM), Helsinki, Finland

*MA and S-KL contributed equally as co-first authors.

\section{Correspondence:}

SIRPA LEPPÄ

sirpa.leppa@helsinki.fi

Received: November 22, 2019.

Accepted: February 17, 2020.

Pre-published: February 20, 2020.

https://doi.org/10.3324/haematol.2019.243626

(C)2021 Ferrata Storti Foundation

Material published in Haematologica is covered by copyright. All rights are reserved to the Ferrata Storti Foundation. Use of published material is allowed under the following terms and conditions:

https://creativecommons.org/licenses/by-nc/4.0/legalcode. Copies of published material are allowed for personal or internal use. Sharing published material for non-commercial purposes is subject to the following conditions:

https://creativecommons.org/licenses/by-nc/4.0/legalcode, sect. 3. Reproducing and sharing published material for commercial purposes is not allowed without permission in writing from the publisher.

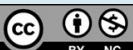

ABSTRACT

The tumor microenvironment (TME) and limited immune surveillance play important roles in lymphoma pathogenesis. Here we aimed to characterize immunological profiles of diffuse large B-cell lymphoma (DLBCL) and predict the outcome in response to immunochemotherapy. We profiled the expression of 730 immune-related genes in tumor tissues of 81 patients with DLBCL utilizing the Nanostring platform, and used multiplex immunohistochemistry to characterize T-cell phenotypes, including cytotoxic T cells (CD8, Granzyme B, OX40, Ki67), T-cell immune checkpoint (CD3, CD4, CD8, PD1, TIM3, LAG3), as well as regulatory T-cells and $\mathrm{T}_{\mathrm{h}} 1$ effector cells (CD3, CD4, FOXP3, TBET) in 188 patients. We observed a high degree of heterogeneity at the transcriptome level. Correlation matrix analysis identified gene expression signatures with highly correlating genes, the main cluster containing genes for cytolytic factors, immune checkpoint molecules, T cells and macrophages, together named a TME immune cell signature. Immunophenotyping of the distinct cell subsets revealed that a high proportion of immune checkpoint positive $T$ cells translated to unfavorable survival. Together, our results demonstrate that the immunological profile of DLBCL TME is heterogeneous and clinically meaningful. This highlights the potential impact of T-cell immune checkpoint in regulating survival and resistance to immunochemotherapy. (Registered at clinicaltrials.gov identifiers: NCT01502982 and NCT01325194.)

\section{Introduction}

Diffuse large B-cell lymphoma (DLBCL) is the most common lymphoma in adults. Approximately $60-70 \%$ of the patients reach long-term remission in response to a combination of rituximab, cyclophosphamide, doxorubicin, and prednisone (R-CHOP) immunochemotherapy. ${ }^{1,2}$ However, $30-40 \%$ of the patients relapse with a dismal prognosis, and a substantial number die from treatment refractory lymphoma.

DLBCL is a result of abnormal B-cell development. Depending on the cell of origin (COO), DLBCL can be divided into germinal-center B-cell like (GCB) and activated $\mathrm{B}$-cell like (ABC) subtypes, ${ }^{3}$ which vary in their gene expression profiles and clinical courses, the ABC-type DLBCL showing worse outcome. ${ }^{4,5}$ Recently, the genomic landscape of DLBCL has been thoroughly dissected and several genomic drivers have been established. ${ }^{6.8}$ The genetic heterogeneity reveals a complex pathogenesis behind DLBCL and highlights a need for personalized therapeutic approaches. 
Tumor microenvironment (TME) surrounding malignant $B$ cells consists of immune cells, such as $T$ lymphocytes, macrophages and natural killer (NK) cells, as well as stromal cells, blood vessels and extracellular matrix (ECM). ${ }^{9,10}$ The composition of immune cells in the TME varies between tumors and is associated with outcome in many cancers,${ }^{11}$ including DLBCL. ${ }^{12-14}$ Chronic inflammation in cancer may affect tumor-infiltrating $T$ cells by inducing exhaustion, a state of dysfunction, where the differentiation, proliferation and effector function of $\mathrm{T}$ cells are suppressed. ${ }^{15}$ This is caused by sustained expression of inhibitory receptors, such as programmed cell death protein 1 (PD1), lymphocyte-activation gene 3 (LAG3), and T-cell immunoglobulin and mucin-domain containing 3 (TIM3) on the surface of $\mathrm{T}$ cells. ${ }^{15}$ With the suppressed immune response, TME can protect tumor cells from immune surveillance. Alternatively, cancer cells may avoid detection through the loss of human leukocyte antigen (HLA) class I and II expression. ${ }^{9,10,16-20}$ However, much is still unknown concerning the impact of TME on the pathogenesis and outcome of DLBCL. In the present study, we sought to further characterize the immune microenvironment in primary DLBCL and find TME-associated prognostic biomarkers.

\section{Methods}

\section{Patients}

The study population consisted of three separate cohorts (Table 1). The gene expression cohort included 81 samples from the patients with primary high-risk DLBCL. The patients were treated in the Nordic LBC-05 and LBC-04 trials with bi-weekly R-CHOEP (rituximab, cyclophosphamide, doxorubicin, etoposide and prednisone) immunochemotherapy and systemic central nervous system (CNS) prophylaxis (high-dose [HD] methotrexate and HDcytarabine)..$^{21,22}$

Immunohistochemistry (IHC) was performed on a total of 188 samples divided into two cohorts. The Nordic Lymphoma Group (NLG) Trial cohort consisted of 51 patients treated in the Nordic NLG-LBC-05 trial. Of these patients, 42 were overlapping with the gene expression cohort. The 137 patients from the Helsinki (HEL)-DLBCL study cohort had been diagnosed with primary DLBCL and treated with R-CHOP or R-CHOEP. Tissue microarrays (TMA) were constructed from primary diagnostic formalinfixed paraffin-embedded (FFPE) tumor tissue. Patients with primary mediastinal B-cell lymphoma were excluded from all cohorts.

The study was approved by the ethics committee in Helsinki, Finland, by the Finnish National Authority for Medicolegal Affairs, and by the Institutional Review Boards of the institutes involved in the study. NLG-LBC-04 and NLG-LBC-05 protocols were registered at clinicaltrials.gov identifiers NCT01502982 and NCT01325194, respectively. All patients signed informed consent before entering the study.

\section{Gene expression profiling}

Digital multiplexed gene expression profiling (GEP) was performed using a Nanostring nCounter Human PanCancer Immunoprofiling Panel (XT-CSO-HIP1-12, NanoString Technologies, Seattle, WA, USA) on primary diagnostic FFPE tumor tissue, as previously described. ${ }^{23}$ The data were analyzed with nSolver 3.0 software (NanoString Technologies) and normalized with the geNorm algorithm. ${ }^{24}$ Further details are available in the Online Supplementary Methods.

\section{Immunohistochemistry}

For multiplex immunohistochemistry (mIHC), T-cell phenotypes were characterized with 4-plex antibody panels using markers for $\mathrm{CD}^{+} \mathrm{T}$-cell regulation (CD3, CD4, TIM3, LAG3), CD8 ${ }^{+} \mathrm{T}$ cell regulation (CD8, PD1, TIM3, LAG3), cytotoxic T cells (CD8, $\mathrm{GrB}, \mathrm{Ki67}, \mathrm{OX} 40$ ), and regulatory $\mathrm{T}$ cells (Treg) and $T_{h} 1 \mathrm{~T}$-cells (CD3, CD4, FOXP3, TBET). Automated digital quantification was performed using CellProfiler software..$^{25}$ Samples with poor staining quality or poor TMA cores were excluded in the subsequent analyses. Molecular subtypes were classified according to Hans' algorithm. ${ }^{26}$ The expression of HLA-DR, HLA-ABC and $\beta 2$ microglobulin (B2M) was evaluated by IHC, as previously described. ${ }^{23}$ More details on $\mathrm{MIHC}$ and $\mathrm{IHC}$ are provided in the Online Supplementary Methods.

\section{In silico immunophenotyping}

CIBERSORTx ${ }^{27}$ was used on publicly available datasets ${ }^{6-8,28}$ to infer the proportions and gene expression profiles (GEP) of infiltrating immune cells. Further details are provided in the Online Supplementary Methods.

\section{Statistical analysis}

Statistical analyses were performed with IBM SPSS v.24.0 (IBM, Armonk, NY, USA) and R v.3.5.1. The prognostic impact was estimated by Cox univariate and multivariate regression analysis (95\% confidence interval). Hierarchical clustering was performed by J-Express Pro $2012^{29}$ using Euclidean distance or Cosine correlation with average linkage for gene or protein expression, respectively. Kaplan-Meier method with log-rank test was used to estimate the difference in survival between the patient groups. Overall survival (OS) and progression-free survival (PFS) were defined as the time from diagnosis until death for OS and progression or death from any other cause for PFS. Mann-Whitney U test and Kruskal-Wallis $\mathrm{H}$ test were used to compare two or more groups, respectively.

\section{Results}

Gene expression analysis reveals distinct tumor microenvironment-associated signatures

Patient demographics are described in Table 1. In the gene expression cohort, median age was 55 years (range 2264) and the majority of patients were males. Disease characteristics were typical of high-risk DLBCL with advanced clinical stage, elevated lactate dehydrogenase $(\mathrm{LDH})$, more than one extranodal (EN) sites, and B symptoms. At a median follow-up of 61 months, 14 patients had relapsed and 11 had died. In this cohort, neither the International Prognostic Index (IPI) score nor the $\mathrm{COO}$ were associated with the outcome.

GEP of DLBCL samples revealed a high degree of heterogeneity. In a correlation matrix analysis of genes with the highest variance, immune cell-related genes created a large cluster, dominating the transcriptome landscape (Figure 1). This signature, denoted as a TME immune cell signature, contained genes encoding markers for $\mathrm{T}$ cells (e.g. $C D 3 D / E / G, C D 8 A / B, C D 2, C D 28)$, macrophages (e.g., $C D 68, C D 163)$, cytolytic factors and NK cells (e.g., GZMB, $P R F$, IFNG, KLRG1), as well as checkpoint molecules (PDCD1 [PD1], CD274 [PD-L1], PDCD1LG2 [PD-L2], HAVCR2 [TIM3], LAG3). In addition to the TME immune cell signature, a B-cell signature (e.g., CD19, MS4A1, $C D 79 A$, and $C D 79 B$ ) and two distinct extracellular matrix (ECM) signatures (signature A, e.g., ITGA2B, ITGB3, ARG, 
Table 1. Patients' demographics.

\begin{tabular}{|c|c|c|c|}
\hline Characteristics & Gene expression cohort n (\%) & NLG-Trial cohort n (\%) & HEL-DLBCL cohort n (\%) \\
\hline N. of patients & $81(100)$ & $51(100)$ & $137(100)$ \\
\hline \multicolumn{4}{|l|}{ Age, years } \\
\hline Median (range) & $55(22-64)$ & $54(22-64)$ & $62(16-84)$ \\
\hline$<60$ & $54(67)$ & $34(67)$ & $60(44)$ \\
\hline$\geq 60$ & $27(33)$ & $17(33)$ & $77(56)$ \\
\hline \multicolumn{4}{|l|}{ Gender } \\
\hline Male & $56(69)$ & $34(67)$ & $75(55)$ \\
\hline Female & $25(31)$ & $17(33)$ & $62(45)$ \\
\hline \multicolumn{4}{|l|}{ Molecular subtype $^{\mathrm{a}}$} \\
\hline $\mathrm{GCB}^{\mathrm{b}}$ & $34(42)$ & $24(52)$ & $58(43)$ \\
\hline Non-GCB & $26(32)$ & $17(37)$ & $66(49)$ \\
\hline nd & $21(26)$ & $5(11)$ & $11(8)$ \\
\hline \multicolumn{4}{|l|}{ WHO PS } \\
\hline $0-1$ & $48(59)$ & $31(61)$ & $98(72)$ \\
\hline$\geq 2$ & $33(41)$ & $20(39)$ & $36(26)$ \\
\hline nd & & & $3(2)$ \\
\hline \multicolumn{4}{|l|}{ Stage } \\
\hline I-II & $8(10)$ & $5(10)$ & $78(57)$ \\
\hline III-IV & $73(90)$ & $46(90)$ & $58(42)$ \\
\hline nd & & & $1(1)$ \\
\hline \multicolumn{4}{|l|}{ IPI } \\
\hline $0-2$ & $19(23)$ & $10(20)$ & $88(64)$ \\
\hline $3-5$ & $62(77)$ & $41(80)$ & $46(34)$ \\
\hline nd & & & $3(2)$ \\
\hline Elevated LDH & $72(89)$ & $45(88)$ & $73(53)^{c}$ \\
\hline $\mathrm{EN}>1$ & $45(56)^{d}$ & $29(57)^{\mathrm{e}}$ & $n \mathrm{~d}^{\mathrm{f}}$ \\
\hline B-symptoms & $52(64)$ & $33(65)$ & $37(27)^{g}$ \\
\hline \multicolumn{4}{|l|}{ Treatment } \\
\hline R-CHOP & & & 120 (88) \\
\hline R-CHOEPh & $81(100)$ & $51(100)$ & $12(9)$ \\
\hline Other & & & $5(4)$ \\
\hline 5-year PFS & $83 \%$ & $86 \%$ & $72 \%$ \\
\hline 5-year OS & $86 \%$ & $88 \%$ & $76 \%$ \\
\hline
\end{tabular}

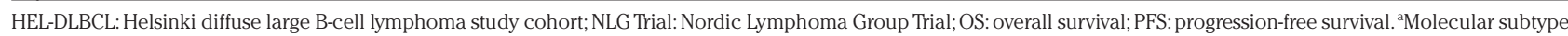
assessed using Hans' algorithm. ${ }^{\mathrm{b}} \mathrm{GCB}$ : germinal center B-cell like; nd: not determined; IPI: International Prognostic Index; LDH: lactate dehydrogenase; EN: extranodal site; RCHOP: rituximab, cyclophosphamide, doxorubicine, vincristine, prednisone; R-CHOEP: R-CHOP+etoposide. ${ }^{C} \mathrm{LDH}$ data was available from 134 patients. ${ }^{\mathrm{d}} \mathrm{EN}$ data available from 72 patients. ${ }^{e} \mathrm{EN}$ data available from 43 patients. Insufficient data. ${ }^{\mathrm{g} B}$-symptoms data available from 131 patients. ${ }^{\text {hPatients }}<65$ years old with high-risk features were treated with RCHOEP-14 and systemic central nervous system prophylaxis consisting of high-dose methotrexate and high-dose cytarabines.

ELANE; and signature B, e.g., FN1, VEGFA, PLAU, COL3A1) were identified. The B-cell signature correlated negatively with the TME immune cell signature (Online Supplementary Figure S1A). Gene signatures separated the patients into distinct groups based on the signature expression (Online Supplementary Figure S1B-E). We identified a subgroup of patients with high expression of the TME immune cell signature (Online Supplementary Figure S2B), resembling an immune cell high or "hot" TME, but, unlike in primary testicular lymphoma, ${ }^{23}$ the signature did not correlate with survival or other clinical parameters (age, stage, performance score, LDH, EN sites) (Online Supplementary Table S1 and Online Supplementary Figure S1F).

\section{Characterization of T-cell subsets in the tumor microenvironment}

To further characterize the immune cell high TME in DLBCL, we performed mIHC focusing on the distinct $\mathrm{T}$ - cell phenotypes using TMA from two independent cohorts (NLG Trial cohort $\mathrm{n}=51$ and HEL-DLBCL cohort $\mathrm{n}=137$ ) (Table 1). Similarly to the gene expression cohort, the NLG trial cohort represented young, high-risk patients. At the median follow-up of 61 months, seven patients had relapsed and six had died. As in the gene expression cohort, neither the IPI score nor the COO was associated with the outcome. In the HEL-DLBCL cohort, the patients were older but had otherwise lower risk characteristics than the patients in the NLG-Trial cohort. At the median follow-up of 53 months, 23 patients had relapsed and 28 had died. Both the IPI score ( $\mathrm{HR}=1.82$, $95 \%$ CI: $1.40-2.38 ; P<0.001$ ), and the COO (GCB vs. nonGCB, HR=2.32, 95\%CI: 1.08-4.99; $P=0.031$ ) were associated with survival.

We used four antibody panels to detect immune checkpoint molecules in $\mathrm{CD}^{+}(\mathrm{CD} 3, \mathrm{CD} 4, \mathrm{TIM} 3$, LAG3) and $\mathrm{CD}^{+} \mathrm{T}$ cells (CD8, TIM3, LAG3, PD1), cytotoxic $\mathrm{CD} 8^{+} \mathrm{T}$ 


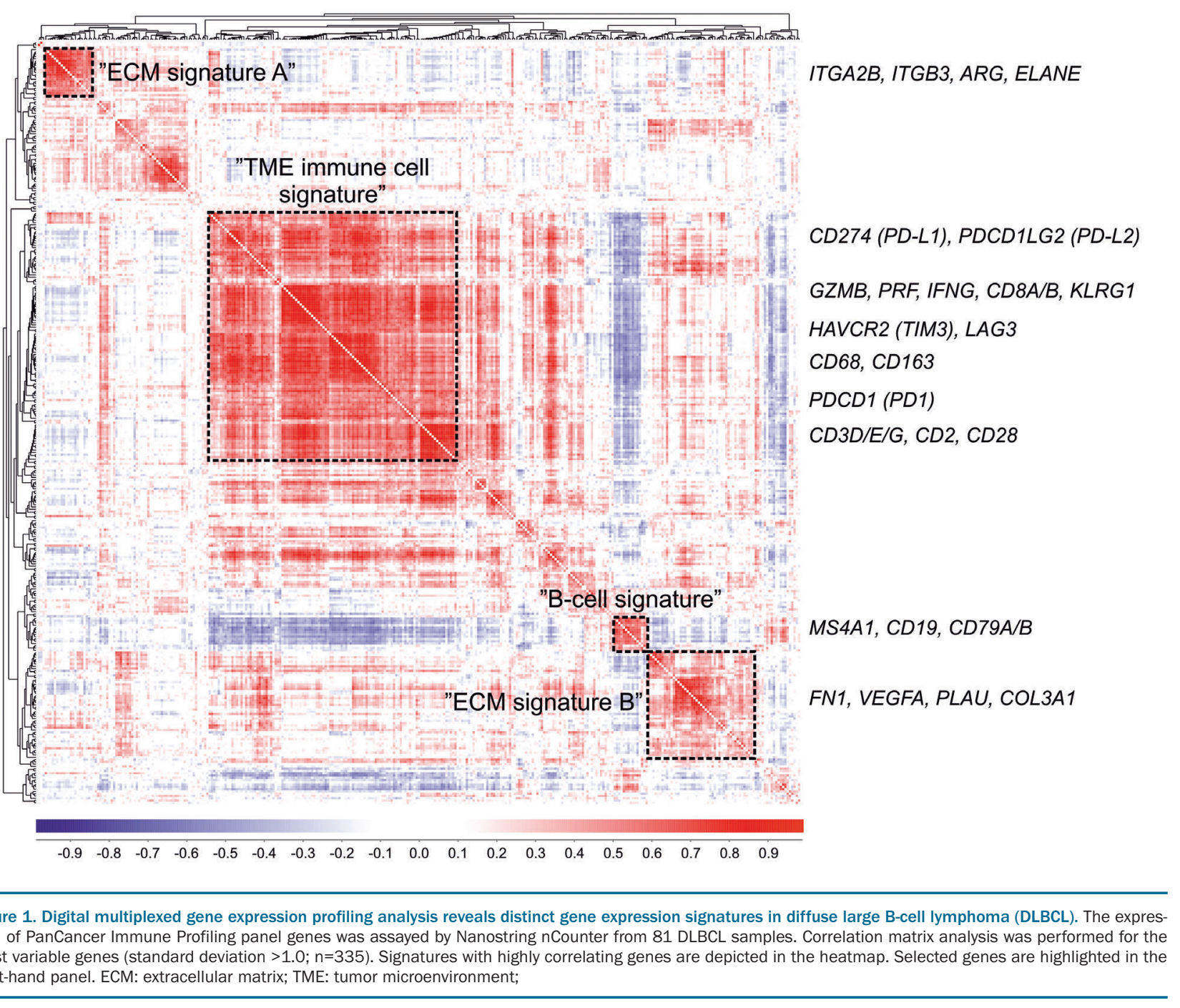

cells (CD8, GrB, OX40 and Ki67), as well as Tregs and $T_{h} 1-$ cells (CD3, CD4, FOXP3 and TBET) (Figure 2A). The number of infiltrating $\mathrm{T}$ cells varied significantly between the patients, dividing them into high and low T-cell groups (Figure 2B). The median numbers of $\mathrm{T}$ cells and their immunophenotypes are presented in Figure 2C and Online Supplementary Table S2. The proportion of $\mathrm{T}$ cells was approximately $16 \%$ (range: $0.1-69 \%$ ). The amount of $\mathrm{CD}^{+}$ $\mathrm{T}$ cells and $\mathrm{CD}^{+} \mathrm{T}$ cells was approximately $6.1 \%$ (range: $0.2-30 \%$ ) and $5.4 \%$ (range: $0.0-42 \%$ ), respectively. Of all $\mathrm{CD}^{+} \mathrm{T}$ cells, Tregs represented $15 \%$ (range: $0.2-51 \%$ ) with considerable variation between the patients. We observed a very low proportion of $\mathrm{TBET}^{+} \mathrm{T}$ cells with a median of $0.04 \%$ (range: $0.0-7.0 \%$ ) of all $\mathrm{CD}^{+} \mathrm{T}$ cells. Of the immune checkpoint molecules, TIM3 was the most abundant with about $8.5 \%$ (range: $0.0-43 \%$ ) of $\mathrm{CD}^{+} \mathrm{T}$ cells and about $5.6 \%$ (range: $0.1-69 \%$ ) of $\mathrm{CD}^{+} \mathrm{T}$ cells staining positive for TIM3. As a proof of concept, expression of the distinct Tcell markers correlated significantly with the corresponding gene expression levels (Online Supplementary Figure S2). Consistent with the gene expression data, the proportion of T cells as such did not associate with survival or patients' demographics (data not shown).

T-cell immunophenotypes showed significant heterogeneity between the patients (Figure 2D and Online
Supplementary Figure S3). Among the patients with a higher proportion of tumor infiltrating T cells, we identified a subgroup with high expression of TIM3, LAG3 and PD1. The expression of these markers in tumor-infiltrating $T$ cells varied from only one to combinations of several immune checkpoint molecules. Additionally, increased proportions of Tregs and $\mathrm{TBET}^{+} \mathrm{T}_{\mathrm{h}} 1$-cells was noted in individual patients.

We next assessed whether DLBCL in general can be divided into T-cell high and low phenotypes. We performed in silico immunophenotyping with CIBERSORTx utilizing four publicly available DLBCL datasets. ${ }^{6-8,28}$ Clustering analyses showed that based on the proportions of $\mathrm{T}$ cells DLBCL is clearly divided into T-cell high and low groups, thus validating our findings (Figure 3 ).

\section{T-cell infiltration correlates with HLA-ABC and $\beta 2$ microglobulin expression}

HLA molecules are essential for T cells to identify antigens and induce immune response. Furthermore, high expression of class I and II HLA molecules on tumor cells is associated with increased $\mathrm{T}$-cell infiltration to the TME. $^{10}$ To evaluate the expression of class I and II HLA molecules in the tumor tissue, we used IHC to analyze the expression of HLA-ABC and B2M, the two components of 
A

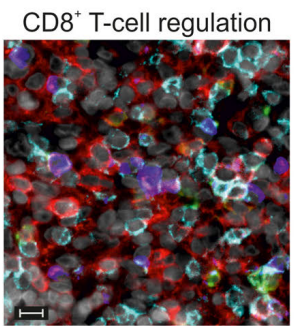

CD8 TIM3 LAG3 PD1

Cytotoxicity

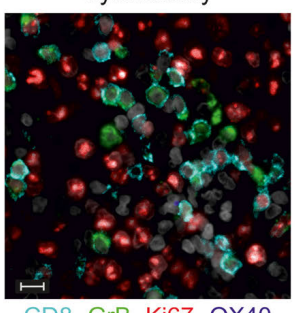

CD8 GrB Ki67 OX40
$\mathrm{CD}^{+} \mathrm{T}$-cell regulation

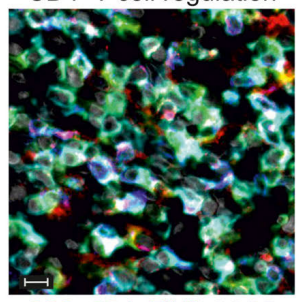

CD3 CD4 TIM3 LAG3

Tregs and $T_{H}$ 1-cells

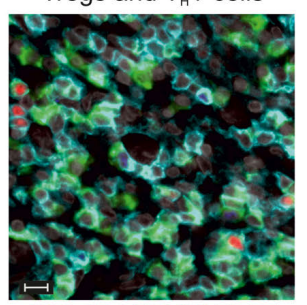

CD3 CD4 FOXP3 TBET

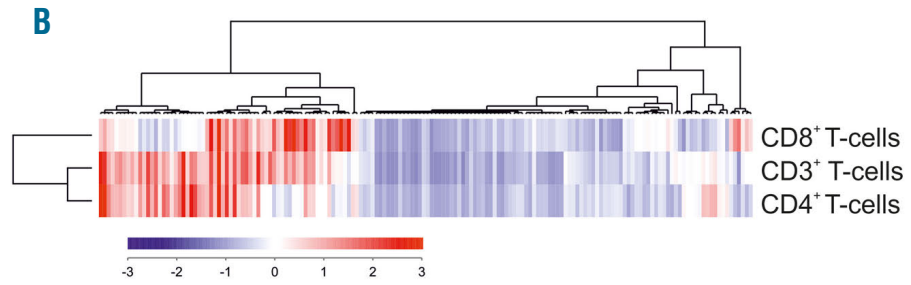

T-cell high

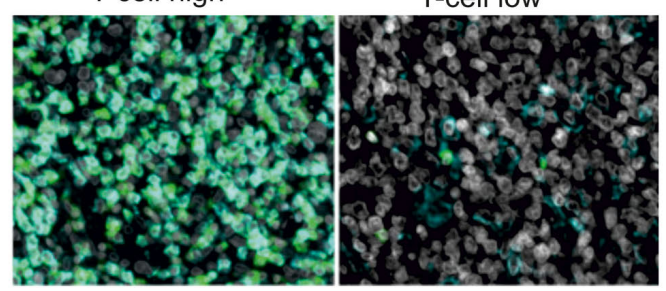

CD3 CD4 DAPI
C

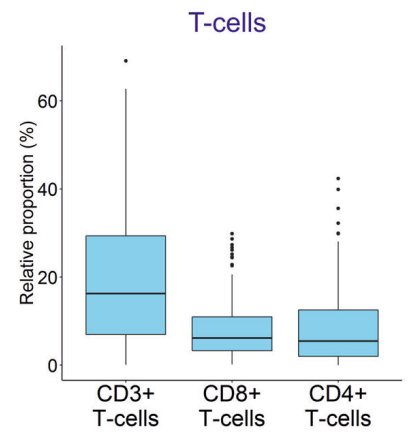

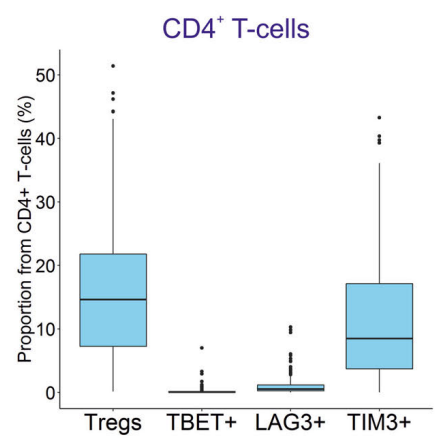

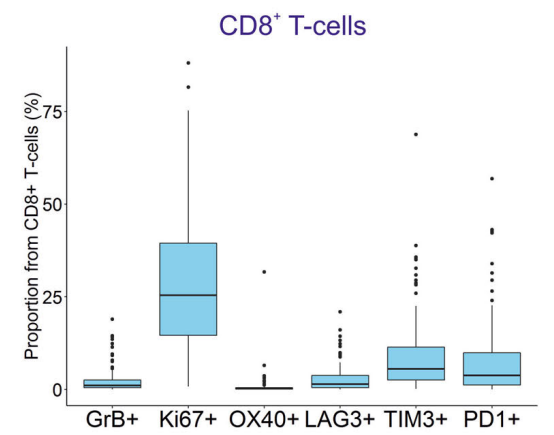

D

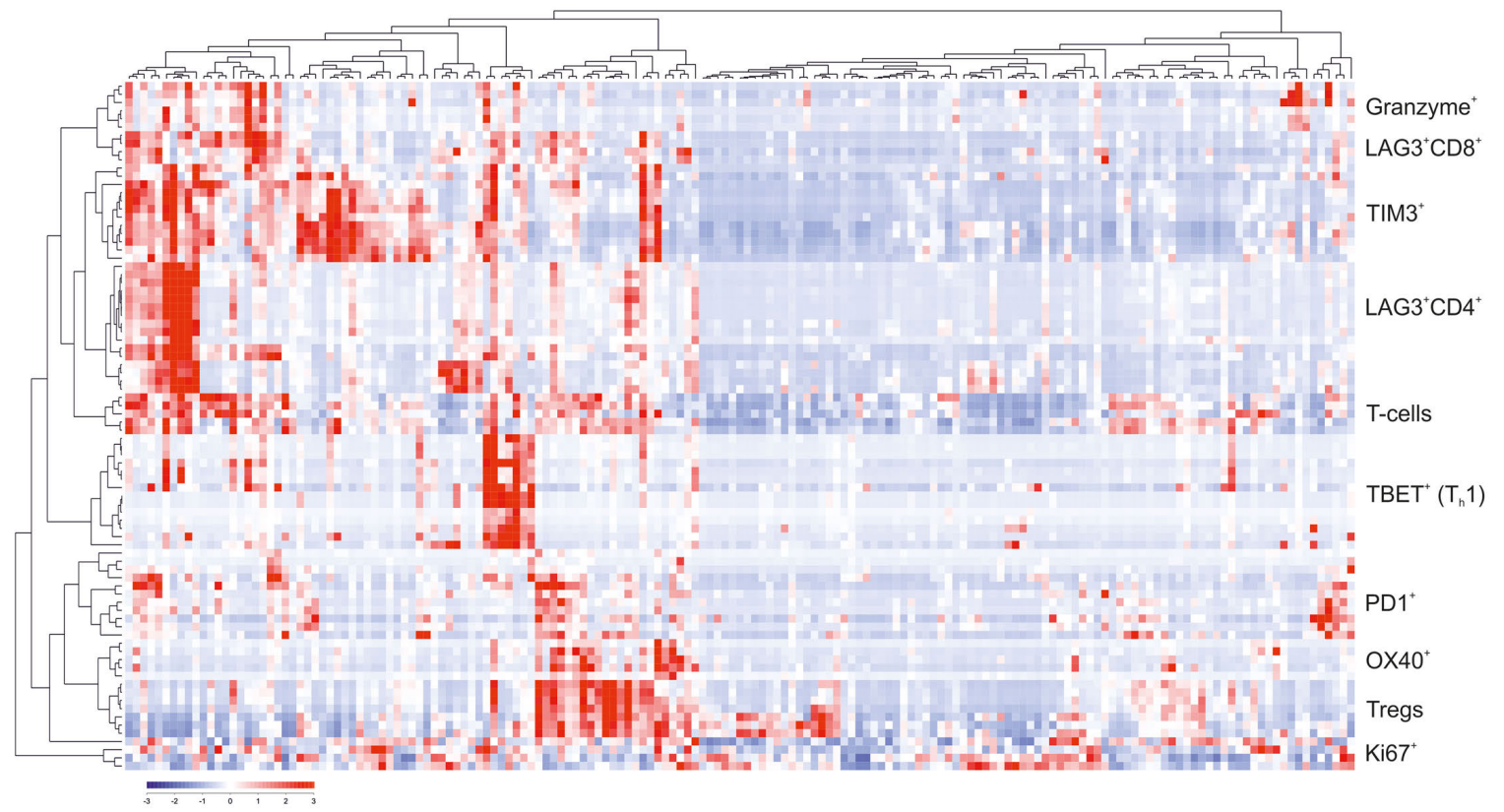

Figure 2. Multiplex immunohistochemistry $(\mathrm{mIHC})$ reveals significant heterogeneity in the diffuse large $\mathrm{B}$-cell lymphoma (DLBCL) tumor microenvironment (TME) (A) Representative images from the 4-plex mlHC analyses performed on tissue microarrays (TMA) from the Helsinki diffuse large B-cell lymphoma study (HEL-DLBCL)

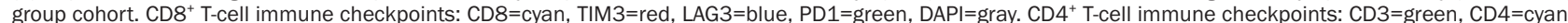
$\mathrm{TIM} 3=$ red, LAG3=blue, DAPI=gray. Cytotoxicity panel: CD8=cyan, Granzyme B=green, Ki67=red, OX40=blue, DAPI=gray. Regulatory $\mathrm{T}$ cells (Tregs) and $\mathrm{T}_{\mathrm{h}} 1$ panel: $\mathrm{CD} 3=$ green, $C D 4=$ cyan, FOXP3=red, TBET=blue, DAPI=gray. Scale bar $10 \mu \mathrm{m}$. (B) Unsupervised hierarchical clustering based on the expression of CD3 ${ }^{+}$, CD4 ${ }^{+}$and CD8 ${ }^{+} \mathrm{T}$ cells. (C) Proportions of distinct immune cells from all cells, from CD4 ${ }^{+} \mathrm{T}$ cells and from $\mathrm{CD} 8^{+}$cells. (D) Heatmap visualizing all quantified immune cells and their immunophenotypes organized by unsupervised hierarchical clustering. Full annotation with all phenotypes is provided in the Online Supplementary Figure S3. 
Table 2. Patients' demographics for the groups with high and low expression of immune checkpoint molecules in the Nordic Lymphoma Group (NLG) Trial and Helsinki-diffuse large B-cell lymphoma study (HEL-DLBCL) cohorts.

\begin{tabular}{|c|c|c|c|c|c|c|}
\hline \multirow[b]{2}{*}{ Characteristics } & \multicolumn{3}{|c|}{ NLG-Trial cohort } & \multicolumn{3}{|c|}{ HEL-DLBCL cohort } \\
\hline & $\begin{array}{c}\text { Low expression } \\
\text { n (\%) }\end{array}$ & $\begin{array}{c}\text { High expression } \\
n(\%)\end{array}$ & $P$ & $\begin{array}{c}\text { Low expression } \\
n(\%)\end{array}$ & $\begin{array}{l}\text { High expression } \\
n(\%)\end{array}$ & $P$ \\
\hline N. of patients & 27 & 19 & & 69 & 50 & \\
\hline Gender & & & 0.016 & & & 0.350 \\
\hline Male & $13(48)$ & $16(84)$ & & $36(52)$ & $31(62)$ & \\
\hline Female & $14(52)$ & $3(16)$ & & $33(48)$ & $19(38)$ & \\
\hline $\begin{array}{l}\text { Age, years } \\
<60 \\
\geq 60\end{array}$ & $\begin{array}{l}19(70) \\
8(30)\end{array}$ & $\begin{array}{l}13(68) \\
6(32)\end{array}$ & 1.000 & $\begin{array}{l}40(58) \\
29(42)\end{array}$ & $\begin{array}{l}12(24) \\
38(76)\end{array}$ & $<0.001$ \\
\hline Molecular subtype $^{a}$ & & & 1.000 & & & 0.847 \\
\hline $\mathrm{GCB}^{\mathrm{b}}$ & $13(50)$ & $8(53)$ & & $28(41)$ & $21(42)$ & \\
\hline Non-GCB & $9(35)$ & $6(40)$ & & $32(46)$ & $27(54)$ & \\
\hline nd & $4(15)$ & $1(7)$ & & $9(13)$ & $2(4)$ & \\
\hline $\begin{array}{l}\text { WHO PS } \\
0-1 \\
\geq 2 \\
\text { nd }\end{array}$ & $\begin{array}{c}20(74) \\
7(26)\end{array}$ & $\begin{array}{l}10(53) \\
9(47)\end{array}$ & 0.209 & $\begin{array}{l}54(78) \\
15(22)\end{array}$ & $\begin{array}{c}33(66) \\
15(30) \\
2(4)\end{array}$ & 0.285 \\
\hline Stage & & & 0.632 & & & 0.347 \\
\hline I-II & $3(11)$ & $1(5)$ & & $43(62)$ & $26(52)$ & \\
\hline III-IV & $24(89)$ & $18(95)$ & & $26(38)$ & $24(48)$ & \\
\hline $\begin{array}{l}\text { IPI } \\
0-2 \\
3-5 \\
\text { nd }\end{array}$ & $\begin{array}{c}6(22) \\
21(78)\end{array}$ & $\begin{array}{l}2(11) \\
17(89)\end{array}$ & 0.440 & $\begin{array}{c}52(75) \\
15(22) \\
2(3)\end{array}$ & $\begin{array}{l}28(56) \\
22(44)\end{array}$ & 0.016 \\
\hline LDH & & & 1.000 & & & 0.573 \\
\hline Low & $3(11)$ & $2(11)$ & & $35(51)$ & $21(42)$ & \\
\hline High & $24(89)$ & $17(89)$ & & $34(49)$ & $27(54)$ & \\
\hline nd & & & & & $2(4)$ & \\
\hline $\begin{array}{c}\mathrm{EN}^{\mathrm{c}} \\
0-1 \\
\geq 2 \\
\text { nd }\end{array}$ & $\begin{array}{c}7(26) \\
15(56) \\
5(19)\end{array}$ & $\begin{array}{c}4(21) \\
12(63) \\
3(16)\end{array}$ & 0.729 & & & \\
\hline Treatment & & & & & & 0.345 \\
\hline R-CHOP & & & & $60(87)$ & $46(92)$ & \\
\hline R-CHOEP & $27(100)$ & $19(100)$ & & $6(9)$ & $3(6)$ & \\
\hline Other & & & & $3(4)$ & $1(2)$ & \\
\hline
\end{tabular}

${ }^{\mathrm{a}}$ Molecular subtype assessed using Hans' algorithm. ${ }^{\mathrm{b}} \mathrm{GCB}$ : germinal center B-cell like; EN: extranodal site; IPI: International Prognostic Index; LDH: lactate dehydrogenase; nd not determined; PFS: progression-free survival; R-CHOP: rituximab, cyclophosphamide, doxorubicine, vincristine, prednisone; R-CHOEP: R-CHOP+etoposide. Insufficient data concerning extranodal sites in the HEL-DLBCL cohort.

class I HLA molecules, as well as HLA-DR, a class II HLA molecule, and correlated the findings with the number of tumor infiltrating $\mathrm{T}$ cells (Figure 4A and B). Positive B2M membrane staining was enriched in the non-GCB subgroup $(P=0.007)$ (Online Supplementary Table S3). As expected, the patients with a negative or moderate expression of HLA-ABC, or negative or perinuclear expression of $\mathrm{B} 2 \mathrm{M}$ had significantly less tumor infiltrating $\mathrm{T}$ cells compared to HLA-ABC and B2M positive cases $(P=0.005$ and $P=0.009$, respectively) (Figure $4 \mathrm{C}$ ). In contrast, no correlation between HLA-DR positivity and the number of $\mathrm{T}$ cells was observed (data not shown).

\section{Higher proportion of immune checkpoint positive $T$ cells in the tumor microenvironment translates to poor outcome}

In the NLG Trial cohort, $43 \%$ of patients had high pro- portions of $\mathrm{TIM}^{+}$and/or $\mathrm{LAG3}^{+}$tumor-infiltrating $\mathrm{T}$ cells (Figure 5A). On the contrary, PD1 levels were low. Interestingly, the patients with a high proportion of $\mathrm{TIM}^{+}$ and $\mathrm{LAG}^{+} \mathrm{T}$ cells had a significantly worse survival than the patients with a lower proportion of these markers (5-year OS 73\% vs. 96\%, $P=0.022$; 5-year PFS 74\% vs. $93 \%, P=0.064$ ) (Figure 5B and Online Supplementary Figure $S 4 A$ ). Baseline characteristics, except gender, were equally distributed between high and low immune checkpoint molecule expressing subgroups (Table 2). In the HELDLBCL cohort, $30 \%$ of patients had a high proportion of $\mathrm{TIM3}^{+}$and/or $\mathrm{LAG3}^{+}$tumor-infiltrating T cells and $42 \%$ of patients had a high proportion of $\mathrm{TIM}^{+}, \mathrm{LAG3}^{+}$, and $\mathrm{PD} 1^{+}$ tumor-infiltrating $\mathrm{T}$ cells (Figure $5 \mathrm{C}$ ). Both a high proportion of $\mathrm{TIM3}^{+}$and $\mathrm{LAG3}^{+}$as well as a high proportion of $\mathrm{TIM}^{+}, \mathrm{LAG}^{+}$, and $\mathrm{PD}^{+}$tumor-infiltrating $\mathrm{T}$ cells translated to poor outcome, validating the finding of the NLG 


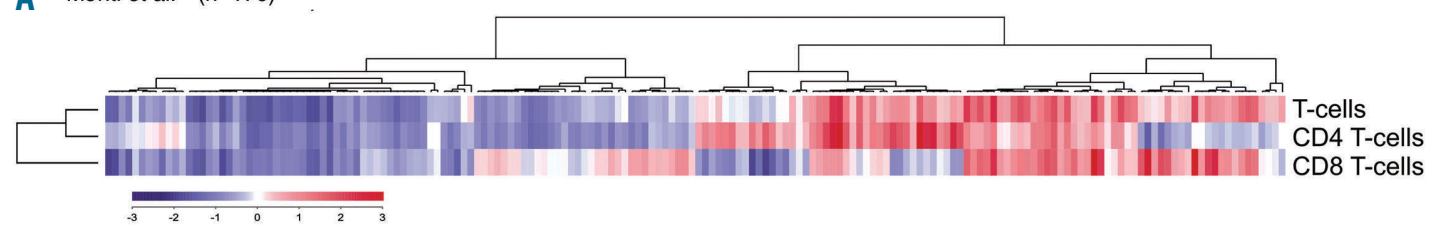

B Reddy et al. ${ }^{6}(\mathrm{n}=624)$

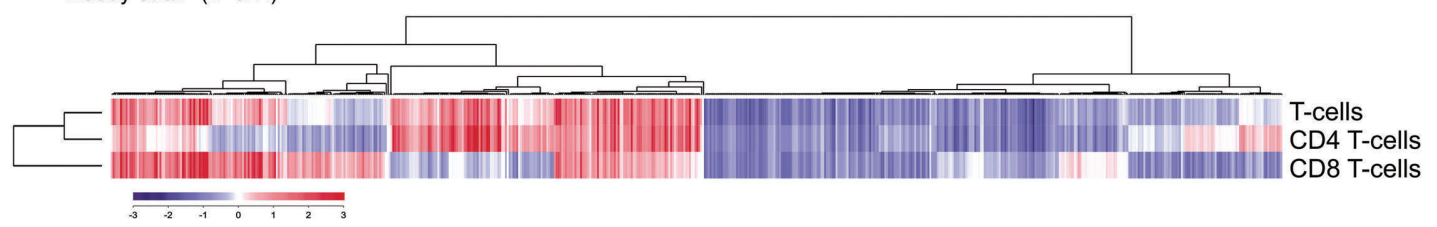

C Schmitz et al. ${ }^{7}(n=562)$

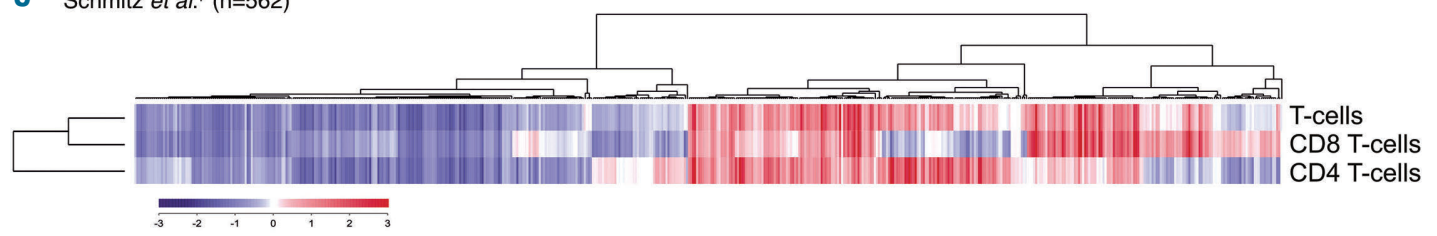

D Chapuy et al. ${ }^{8}(n=137)$

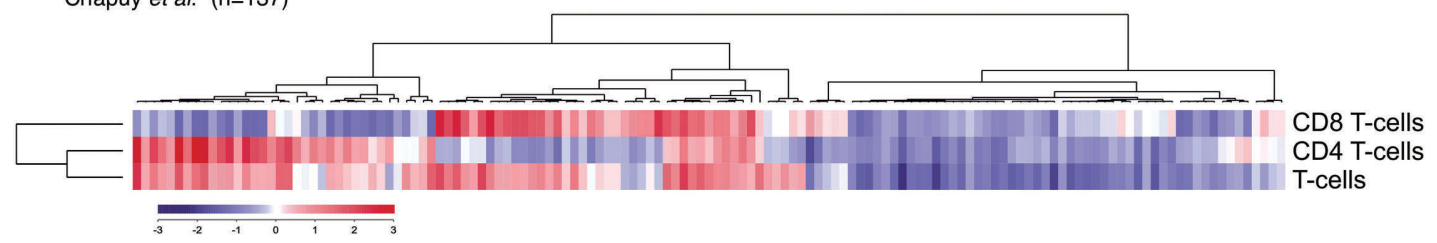

Figure 3. Diffuse large B-cell lymphoma (DLBCL) can be dived into T-cell high and low phenotypes. In silico immunophenotyping with CIBERSORTx was used to deconvolute T-cell proportions based on gene expression in four publicly available datasets. ${ }^{6-8,28}$ Gene expression datasets were uploaded to the CIBERSORTX web portal and the algorithm run using the 547-gene Leukocyte gene signature matrix (LM22) at 100 permutations. T-cell data were z-score transformed and visualized by unsupervised hierarchical clustering.

Trial cohort (5-year OS 66\% vs. 79\%, $P=0.029$, and 5 -year PFS $60 \%$ vs. $76 \%, P=0.035$ ) (Figure $5 \mathrm{D}$ and Online Supplementary Figure $S 4 B$ ). Survival association was particularly seen in patients with the non-GCB phenotype and high IPI score (Figure 5E and F, and Online Supplementary Figure S5). When the groups with low and high expression of immune checkpoint molecules were compared, high expression was found to associate with age, high IPI score (Table 2) and HLA-ABC positivity $(P=0.037)$ (Online Supplementary Table S4A). HLA-ABC positivity tended also to be enriched in the patients with higher proportions of LAG3 $^{+} \mathrm{T}$ cells $(P=0.067)$ (Online Supplementary Table S4B). However, no correlation was found between immune checkpoint expression in $\mathrm{T}$ cells and B2M or HLA-DR expression (data not shown).

\section{TIM3 is an independent predictor for survival in diffuse large B-cell lymphoma patients}

Of the individual immune checkpoint molecules, high TIM3 expression was associated with inferior survival in both cohorts (Figure 6A-D and Online Supplementary Figure S6), and was independent of the IPI and COO (Online Supplementary Figure S7). In addition, high proportions of $\mathrm{TIM}^{+} \mathrm{T}$ cells from all $\mathrm{T}$ cells, $\mathrm{TIM}^{+} \mathrm{CD} 4^{+} \mathrm{T}$ cells from all $\mathrm{CD}^{+} \mathrm{T}$ cells, as well as $\mathrm{TIM}^{+} \mathrm{CD}^{+}$cells from all $\mathrm{CD}^{+}$ cells translated to poor outcome in the HEL-DLBCL cohort (Figure 6A, B, E-G), all independent of the IPI. All except a high proportion of $\mathrm{TIM}^{+} \mathrm{T}$ cells from all T cells were also independent of the COO (Online Supplementary Figure S7). On the contrary, the proportions of $\mathrm{TIM}^{+} \mathrm{CD} 8^{+} \mathrm{T}$ cells or $\mathrm{PD}^{+}$or $\mathrm{LAG3}^{+}$cells did not associate with survival. Besides a high proportion of $\mathrm{TIM}^{+} \mathrm{T}$ cells, a high proportion of $\mathrm{TIM}^{+} \mathrm{CD}^{+} \mathrm{CD}^{-}$cells from all $\mathrm{CD}^{+}{ }^{+} \mathrm{CD}^{-}$cells correlated with poor outcome in both cohorts (Figure 6A, $\mathrm{B}$ and $\mathrm{H}$ ), independent of the IPI and $\mathrm{COO}$ (Online Supplementary Figure S7). These cells might represent macrophages since according to the CIBERSORTx analysis TIM3 is expressed in monocytes/macrophages and neutrophils in addition to $\mathrm{T}$ cells (Online Supplementary Table S5). Interestingly, in the NLG-Trial cohort TIM3 expression correlated positively with the gene expression of IFNG $(P=0.449, P=0.003)$ and several other cytokines (Online Supplementary Table S6).

Characterization of the cytotoxic and regulatory T cells in the tumor microenvironment

In both cohorts, when studying expression of cytotoxicity-related markers, patients with high proportion of Granzyme B ${ }^{+}$cells were distinct from the rest $(24 \%$ in the NLG Trial cohort and $14 \%$ in the HEL-DLBCL cohort) (Online Supplementary Figure S8A). Granzyme B positivity translated to poor outcome in the HEL-DLBCL cohort (5year OS $50 \%$ vs. 78\%, $P=0.029$; 5 -year PFS $53 \%$ vs. $72 \%$, $P=0.076$ ) (Online Supplementary Table S7 and Online 
A

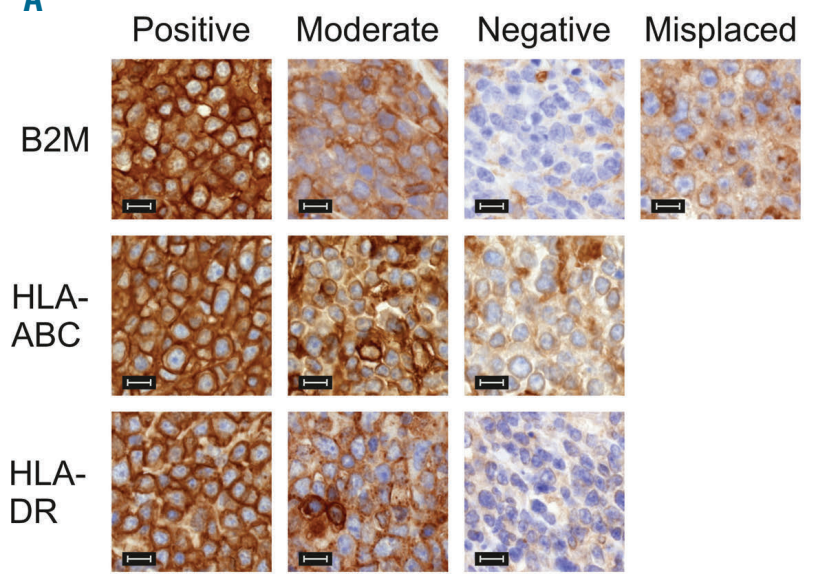

B

\begin{tabular}{lcccc} 
& Positive & Moderate & Negative & Misplaced \\
\hline B2M (\%) & 24 & 50 & 18 & 7 \\
HLA-ABC (\%) & 48 & 48 & 3 & na \\
HLA-DR (\%) & 35 & 48 & 17 & na \\
\hline
\end{tabular}

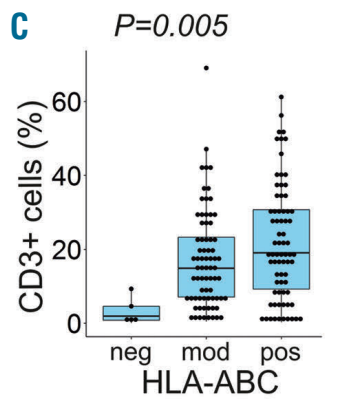

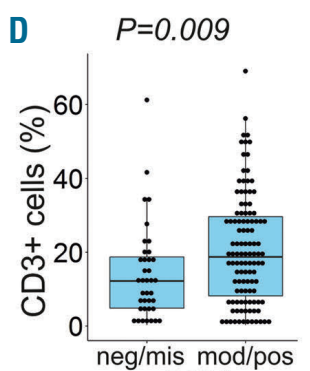

B2M

Figure 4. Membranous expression of HLA-ABC and $\beta 2$ microglobulin (B2M) correlates with increased T-cell infiltration. (A) Representative images from B2M, HLA$\mathrm{ABC}$, and HLA-DR immunohistochemical (IHC) stainings. Scale bar $10 \mu \mathrm{m}$. (B) Results of the B2M, HLA-ABC, and HLA-DR IHC scoring. (C and D) Box plots visualizing the association of $\mathrm{CD}^{+}$T cells with HLA-ABC (C) and B2M (D) scores. P-values were determined by Kruskall-Wallis $H(C)$ and Mann-Whitney $U$ tests (D).

Supplementary Figure S8B), but not in the NLG Trial cohort (data not shown). Furthermore, a small group of patients $(13 \%)$ characterized with high proportions of OX $40^{+}$and $\mathrm{Ki}^{+} \mathrm{CD}^{+} \mathrm{T}$ cells was identified in the HEL-DLBCL cohort. OX40 and Ki67 positivity trended for superior prognosis (Online Supplementary Figure S8C). FOXP3 ${ }^{+}$ Tregs were frequent in $30 \%$ of the patients in the NLGTrial cohort and were associated with inferior outcome (5year OS $70 \%$ vs. 94\%, $P=0.041$; 5 -year PFS $71 \%$ vs. $91 \%$, $P=0.101$ ) (Online Supplementary Table S8 and Online Supplementary Figure S9). However, the finding could not be validated in the HEL-DLBCL cohort (data not shown). Neither did we observe any correlation between TBET $^{+}$ $\mathrm{T}_{\mathrm{h}} 1$-cells and outcome (data not shown).

\section{Discussion}

In this study, we applied GEP and MIHC with digital image analysis to characterize tumor infiltrating $T$ cells in patients with primary DLBCL. We found a heterogeneous TME with lymphomas differing significantly in the number and subtype of tumor-infiltrating $T$ cells. First, we identified a TME immune cell signature, which separated the patients into immune cell high or "hot" and "cold" subgroups. However, the signature did not associate with survival. In contrast, the presence of $T$ cells expressing immune checkpoint molecules in the TME, and especially T cells expressing TIM3 translated to poor outcome in patients treated with standard immunochemotherapy. Similar results were observed in two independent cohorts despite differences in their clinical variables, implying that the prognostic impact of the TME cytotypes is not limited to a particular patient population. Together, the findings underscore the regulatory impact of $\mathrm{T}$ cells on therapy resistance and survival in primary DLBCL.

Recent comprehensive genome and transcriptome studies have shed light on the heterogeneity of DLBCL, and based on genomic drivers, uncovered multiple DLBCL subtypes, which differ phenotypically and clinically. ${ }^{6-8}$ Our study, focusing on the characterization of TME, illustrates the diversity of the DLBCL even further. The observed variations in the amounts of the tumor-infiltrating immune cells and their phenotypes, as well as association with prognosis, highlight the clinical importance of the crosstalk between tumor cells, TME and host response.

To date, the impact of T-cell immune checkpoint expression on the pathogenesis and clinical outcome of DLBCL has been relatively scarcely studied, and has mainly focused on the role of the immune checkpoint receptor $\mathrm{PD} 1 .^{30}$ In one study, a high proportion of $\mathrm{PD}^{+} \mathrm{CD}^{+} \mathrm{T}$ cells and PD-L1 ${ }^{+} \mathrm{T}$ cells in the TME was found to predict poor survival in DLBCL, whereas high expression of the immune checkpoint cytotoxic T-lymphocyte-associated protein 4 (CTLA4) on T cells was associated with favorable outcome. ${ }^{14}$ In another study, Tcell immunoglobulin and ITIM domain (TIGIT) expression in tumor infiltrating $\mathrm{T}$ cells was identified as a suppressor of T-cell mediated antitumor activity in B-cell lymphomas. ${ }^{31}$ A recent study has also found a high TIM3 expression to correlate with poor prognosis. ${ }^{32}$ However, specific subtyping of these TIM3-expressing cells was not addressed. Additionally, expression of TIM3, LAG3 and $\mathrm{PD} 1$ on $\mathrm{CD}^{+} \mathrm{T}$ cells was recently shown not only to represent exhausted $\mathrm{T}$ cells but also a population of highly active $T$ cells, and that other factors in the TME might affect the cells in eventually becoming exhausted. ${ }^{33}$ In our study, the proportion of $\mathrm{PD} 1^{+} \mathrm{T}$ cells alone did not correlate with survival. Instead, we found that high proportions of $\mathrm{TIM}^{+} \mathrm{T}$ cells from all $\mathrm{T}$ cells, $\mathrm{TIM}^{+} \mathrm{CD} 4^{+} \mathrm{T}$ cells, $\mathrm{TIM}^{+} \mathrm{CD}^{+}$cells from all $\mathrm{CD}^{+}$cells and $\mathrm{TIM}^{+} \mathrm{CD}^{+} \mathrm{CD}^{-}$cells have independent adverse impact on survival. The results suggest that TIM3 might identify a particular subgroup of $\mathrm{T}$ cells possibly associated with immune exhaustion. However, mechanistic experiments proving the association of T-cell dysfunction with TIM3 expression and poor prognosis are warranted. Given the positive correlation between TIM3 and IFNG gene expression, it is also possible that the $\mathrm{TIM}^{+}$cell population in DLBCL TME is heterogeneous and consists of cells with both exhausted and active phenotypes.

Checkpoint inhibitors targeting PD1 and CTLA4 have 
A

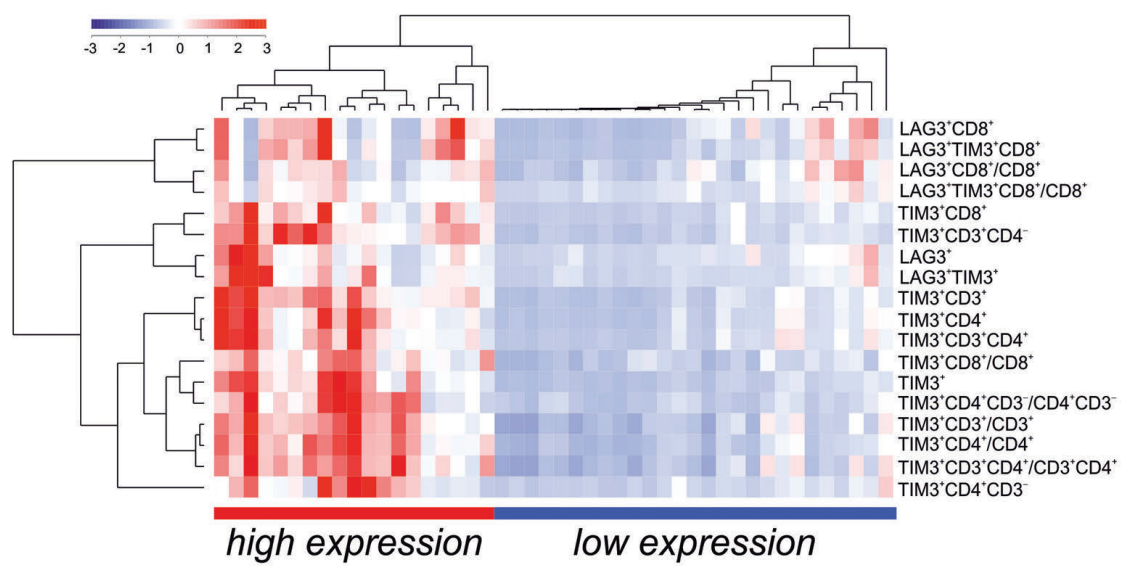

B

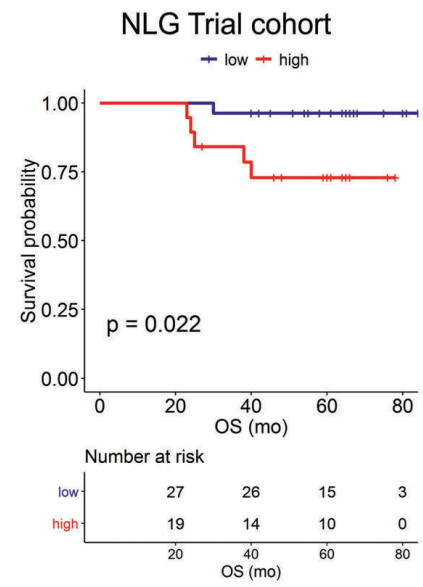

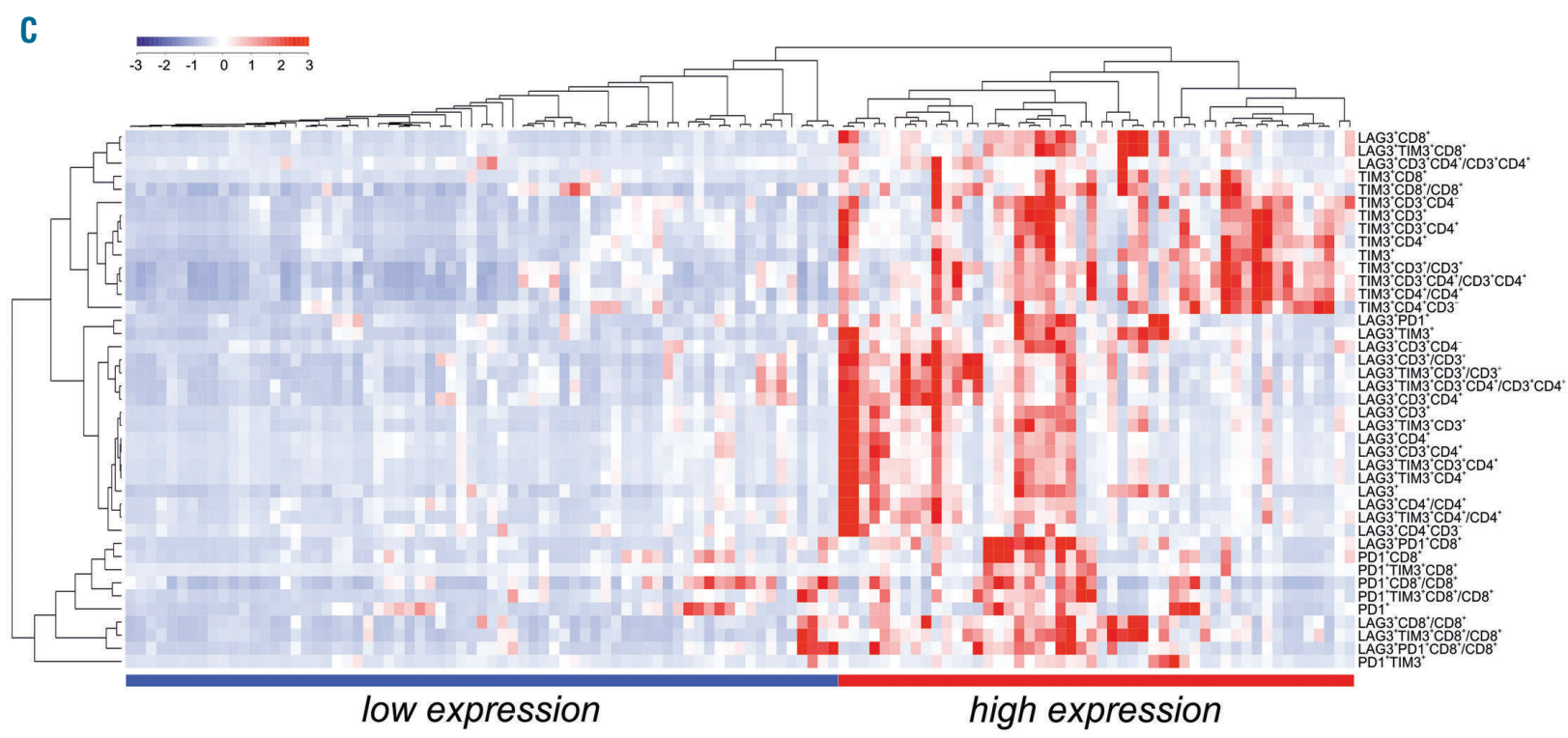

D

HEL-DLBCL cohort

+ low - high

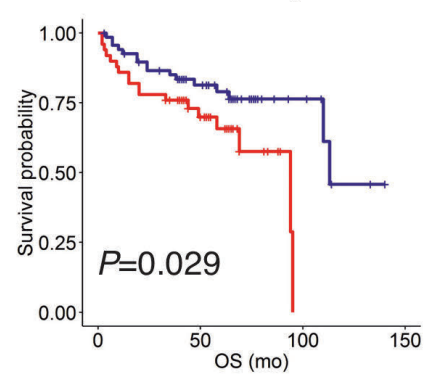

Number at risk

low. $69 \quad 40 \quad 7 \quad 0$

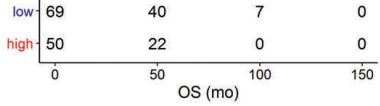

E

IPI $>1$ (HEL-DLBCL)

+ low - high

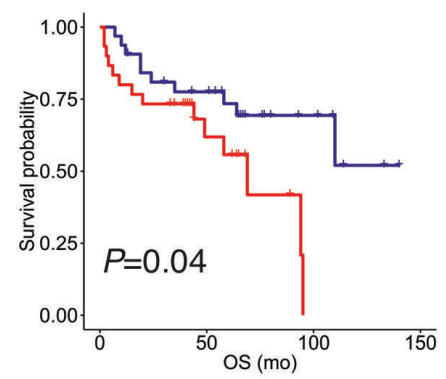

high. \begin{tabular}{rrrr} 
Number at risk \\
32 & 22 & 6 & 0 \\
30 & 10 & 0 & 0 \\
\hline 0 & 50 & OS $(\mathrm{mo})$ &
\end{tabular}
F

non-GCB (HEL-DLBCL)

+ low - high

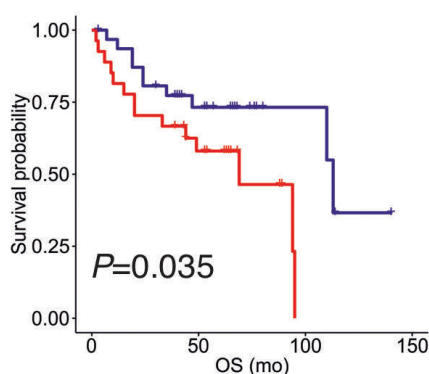

Number at risk

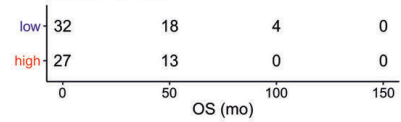

Figure 5. A high proportion of T cells expressing immune checkpoint molecules in the tumor microenvironment (TME) correlates with worse outcome in patients with diffuse large B-cell lymphoma (DLBCL). (A) The multiplex immunohistochemistry (mIHC) data from the Nordic Lymphoma Group (NLG) Trial cohort was clustered according to the proportions of $\mathrm{TIM}^{+} \mathrm{T}$ cells and LAG3 expressing CD8 ${ }^{+} \mathrm{T}$ cells. (B) Kaplan-Meier (log-rank test) survival plots depict overall survival (OS) in months (mo) in the groups with high and low amounts of these immune checkpoint molecule-expressing T cells in the NLG Trial cohort. (C) Unsupervised hierarchical clustering of T cells expressing immune checkpoint molecules in the Helsinki diffuse large B-cell lymphoma (HEL-DLBCL) cohort. (D) Kaplan-Meier (log-rank test) survival plots depict OS in the groups with high and low amounts of T cells expressing TIM3, LAG3 and PD1 in the HEL-DLBCL cohort. (E and F) Kaplan-Meier (log-rank test) survival plots depict OS in the groups with a high and low expression of immune checkpoint molecules in patients with an International Prognostic Index (IPI) score over $1(E)$ and in patients with non-GCB type DLBCL (F) in the HEL-DLBCL cohort. N=46 for (A and B) and N=119 for (C-F). (Samples having tissue microarrays spots with poor quality for any of the phenotypes were removed from the clustering and survival analyses). 
been tested in phase I trials for the patients with relapsed/refractory DLBCL with promising results. ${ }^{34,35}$ However, in comparison to Hodgkin lymphoma, and according to a recently reported phase II trial with relapsed/refractory DLBCL, response rates to single agent PD1 blockade are low. ${ }^{36}$ It is possible that lower incidence and magnitude of 9p24.1 alterations translating to lower PD-L1 expression in tumor cells in comparison to classic

A

NLG Trial cohort

\begin{tabular}{|c|c|c|c|}
\hline Cell type & $\mathrm{HR}(95 \% \mathrm{Cl})$ & & value \\
\hline $\mathrm{CD} 3+(n=51)$ & $1.05(0.68-1.60)$ & $\rightarrow$ & 0.816 \\
\hline $\mathrm{CD} 4+(\mathrm{n}=51)$ & $1.20(0.63-2.30)$ & $\rightarrow$ & 0.585 \\
\hline $\mathrm{CD} 3+\mathrm{CD} 4+(\mathrm{n}=51)$ & $1.15(0.54-2.40)$ & $\rightarrow$ & 0.724 \\
\hline $\mathrm{CD} 8+(n=50)$ & $0.73(0.22-2.40)$ & $\longrightarrow$ & 0.612 \\
\hline \multicolumn{4}{|l|}{ Immune checkpoint molecules } \\
\hline LAG3 $+(n=51)$ & $1.84(0.00072-4700)$ & $\bullet \longrightarrow$ & 0.879 \\
\hline$P D 1+(n=49)$ & $1.15(0.22-6.00)$ & $\bullet$ & 0.868 \\
\hline TIM3+ $(n=51)$ & $2.93(1.00-8.20)$ & $\longrightarrow$ & 0.041 \\
\hline \multicolumn{4}{|l|}{ TIM3+ cells (ratios) } \\
\hline TIM3+CD3+/CD3+ $(n=51)$ & $1.88(0.91-3.90)$ & $\because$ & 0.086 \\
\hline TIM3+CD4+/CD4+ (n=51) & $1.80(0.88-3.70)$ & $\rightarrow$ & 0.107 \\
\hline TIM3+CD3+CD4+/CD3+CD4+ $(n=51)$ & $5.14(0.064-410)$ & $\longrightarrow$ & 0.464 \\
\hline TIM3 $+C D 8+/ C D 8+(n=49)$ & $1.45(0.0084-250)$ & $\longrightarrow$ & 0.887 \\
\hline TIM3 + CD $4+C D 3-/ C D 4+C D 3-(n=51)$ & $2.40(1.00-5.70)$ & 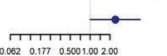 & 0.049 \\
\hline
\end{tabular}

C

C $\quad \operatorname{TIM3}^{+}$(NLG Trial)

+ low + high

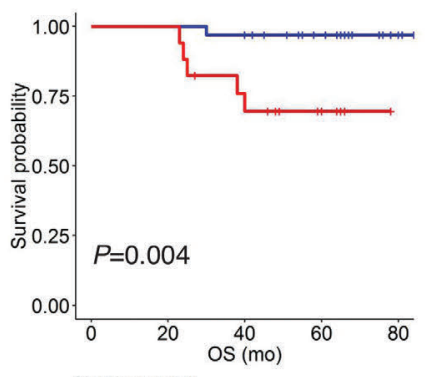

Number at risk

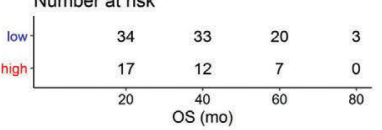

F $\mathrm{TIM}^{+} \mathrm{CD}^{+} \mathrm{CD}^{+} / \mathrm{CD} 3^{+} \mathrm{CD} 4^{+}$

+ low + high

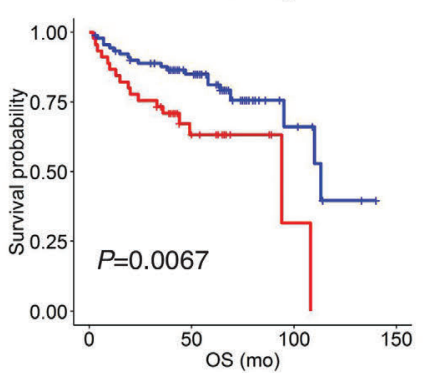

Number at risk

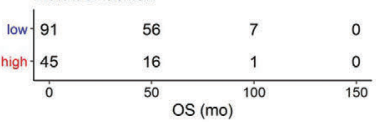

Hodgkin lymphoma explains at least to some extent why the majority of the DLBCL patients do not benefit from single agent checkpoint blockade. Another explanation may be that the non-immune mechanisms or alternative immune checkpoints are upregulated and thereby have more clinical impact in DLBCL. Our results suggest that blockade of TIM3 and/or LAG3 might be beneficial in DLBCL patients with immune checkpoint expressing

B

\section{HEL-DLBCL cohort}

\begin{tabular}{|c|c|c|c|}
\hline Cell type & $\mathrm{HR}(95 \% \mathrm{Cl})$ & & -value \\
\hline $\operatorname{CD} 3+(n=137)$ & $1.02(0.80-1.30)$ & - & 0.844 \\
\hline $\mathrm{CD} 4+(n=137)$ & $1.00(0.75-1.30)$ & $\rightarrow$ & 0.991 \\
\hline $\mathrm{CD} 3+\mathrm{CD} 4+(\mathrm{n}=137)$ & $1.10(0.73-1.70)$ & $\rightarrow-$ & 0.645 \\
\hline$C D 8+(n=130)$ & $0.74(0.42-1.30)$ & $\rightarrow$ & 0.314 \\
\hline \multicolumn{4}{|l|}{ Immune checkpoint molecules } \\
\hline LAG3+ $(n=137)$ & $0.58(0.004-78.0)$ & $\longleftrightarrow$ & 0.827 \\
\hline $\mathrm{PD} 1+(n=128)$ & $1.66(0.51-5.40)$ & $\longrightarrow$ & 0.400 \\
\hline TIM3+ (n=137) & $2.62(1.40-4.80)$ & $\rightarrow-$ & 0.002 \\
\hline \multicolumn{4}{|l|}{ TIM3+ cells (ratios) } \\
\hline TIM3+CD3+/CD3+ $(n=136)$ & $1.53(1.10-2.20)$ & $\rightarrow$ & 0.017 \\
\hline TIM3+CD4+/CD4+ $(n=136)$ & $1.72(1.20-2.50)$ & $\rightarrow$ & 0.003 \\
\hline $\mathrm{TIM} 3+\mathrm{CD} 3+\mathrm{CD} 4+/ \mathrm{CD} 3+\mathrm{CD} 4+(\mathrm{n}=136)$ & $1.44(1.10-1.90)$ & $\rightarrow$ & 0.013 \\
\hline $\mathrm{TIM} 3+\mathrm{CD} 8+/ \mathrm{CD} 8+(\mathrm{n}=128)$ & $1.20(0.82-1.80)$ & $\rightarrow$ & 0.349 \\
\hline TIM3+CD4+CD3-/CD4+CD3- $(n=136)$ & $2.29(1.50-3.50)$ & $\rightarrow$ & $<0.001$ \\
\hline
\end{tabular}

D TIM3 $^{+}(\mathrm{HEL-DLBCL})$

+ low - high

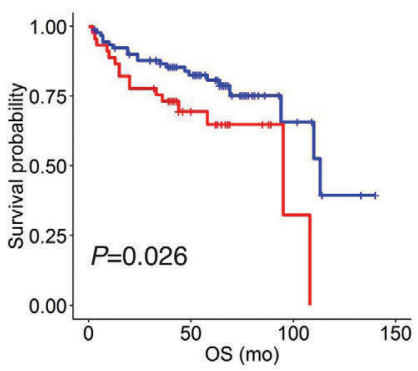

Number at risk

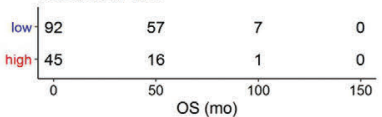

G $\quad \mathrm{TIM3}^{+} \mathrm{CD}^{+} / \mathrm{CD} 4^{+}$

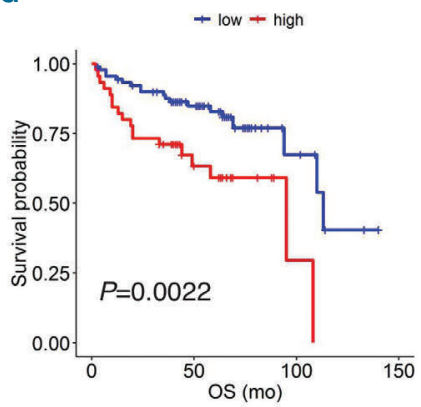

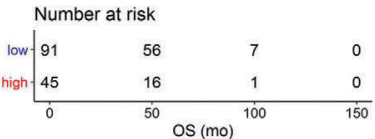

E $\quad \mathrm{TIM3}^{+} \mathrm{CD} 3^{*} / \mathrm{CD} 3^{+}$

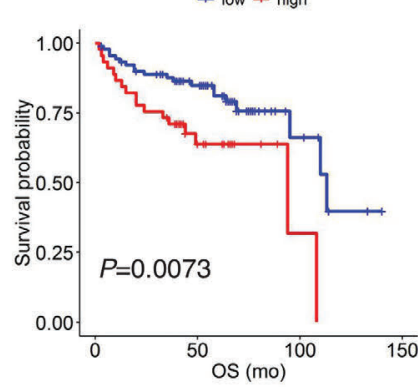

Number at risk

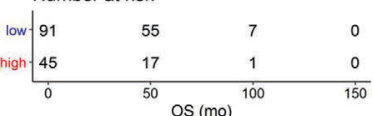

H $\quad \mathrm{TIM}^{+} \mathrm{CD} 4^{+} \mathrm{CD} 3 / \mathrm{CD} 4^{+} \mathrm{CD} 3$

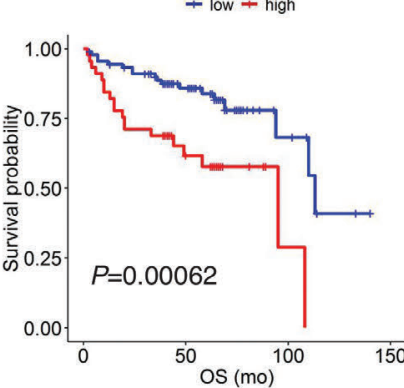

Number at risk

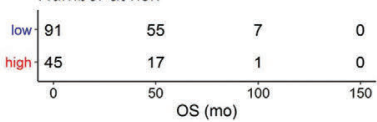

Figure 6. The impact of immune checkpoint molecules and distinct T-cell subtypes on survival. (A and B) Forest plots visualizing the impact of T cells and their immunophenotypes on overall survival (OS) in months (mo) in the Nordic Lymphoma Group (NLG) Trial (A) and Helsinki diffuse large B-cell lymphoma study (HELDLBCL) (B) cohorts, as evaluated using Cox univariate tests with continuous variables. (C-H) Kaplan-Meier plots (log-rank test) visualizing survival associations of distinct $\mathrm{TIM}^{+}$cell subpopulations. Cut-off was set at the highest expressing one-third versus the lowest expressing two-thirds. 
T-cell phenotypes. They also provide a rationale for testing combination treatment strategies in this context. Interestingly, in preclinical studies, use of a dual therapy with PD1 and TIM3 blockades has been demonstrated to improve efficacy in comparison to single agent PD1 targeted therapy in solid tumors and acute myeloid leukemia. ${ }^{37-40}$ A recent report further shows that combining checkpoint inhibitors with chimeric antigen receptor $T$ cells might also be potent in DLBCL. ${ }^{41}$

The focus of our study was to characterize tumor-infiltrating lymphocytes in DLBCL. However, we also identified a population of $\mathrm{TIM3}^{+} \mathrm{CD}^{+} \mathrm{CD}^{-}$cells which had a significant adverse impact on the outcome of patients in both cohorts. Considering CD4 positivity, these cells are likely to represent monocytes/macrophages, dendritic cells, or NK cells. ${ }^{42-44}$ In fact, our in silico immunophenotyping utilizing CIBERSORTx suggests that tumor infiltrating monocytes/macrophages express TIM3. However, the true identity of the $\mathrm{TIM}^{+} \mathrm{CD}^{+}{ }^{+} \mathrm{CD}^{-}$cells requires further validation.

We also identified a subgroup of patients characterized by a large proportion of tumor-infiltrating cytotoxic cells and Tregs. Data suggesting that a large proportion of cytotoxic cells in the TME translates to inferior survival contradict the concept that cytotoxic $\mathrm{T}$ cells act as killers of tumor cells. However, previous studies have also reported an inferior effect of tumor-infiltrating cytotoxic cells on the outcome in Hodgkin's lymphoma, ${ }^{45-47}$ and also in DLBCL. ${ }^{48}$ Oudejans et al. ${ }^{47}$ speculated that in tumors with a larger proportion of cytotoxic cells, malignant cells might be more resistant to cell-mediated killing, which would explain the relatively poorer outcome of these patients. This resistance might also reflect refractoriness of the disease to standard therapies as immune cells may partly mediate the effect of chemotherapy. ${ }^{49}$ In contrast to previous studies on different lymphoma entities, ${ }^{45,46,50,51}$ higher proportion of Tregs was associated with poor survival in the NLG Trial cohort but this observation could not be validated in the HEL-DLBCL cohort. The conflicting results may be explained by heterogeneous patient populations, cytokines produced by Tregs and the complex interplay between the cells in the TME. Nevertheless, further research is needed to validate our findings and to determine the role of cytotoxic cells and Tregs in the DLBCL TME.

In conclusion, our results demonstrate a novel adverse prognostic impact of immune checkpoint expressing $T$ cells, especially TIM3 ${ }^{+} \mathrm{T}$ cells, on the survival of DLBCL patients in response to standard immunochemotherapy. Additional research on the effect of TME and checkpoint blockage on the outcome of DLBCL is warranted. It will be interesting to test whether a subset of patients with immune checkpoint positive T cells may be more likely to respond to PD1 inhibition, or if combination therapies with TIM3 and/or LAG3 inhibitors can further improve the outcome.

\section{Disclosures}

$S M$ has received honoraria and research funding from Novartis, BMS and Pfizer (not related to this study); SL has received honoraria and research funding from Roche, Novartis, Celgene, Takeda, Bayer and Janssen-Cilag (not related to this study). Other authors have no conflicts of interest to disclose.

\section{Contributions}

$M A$ and S-KL designed and conceived the study, analyzed data, and wrote the manuscript; $O B$ participated in designing the MIHC analyses; SM provided guidance and support; JMJ, $M-L K-L, K B$ and $H H$ provided samples; TP designed and performed MIHC data analyses; SL designed and supervised the study and wrote the manuscript. All authors have read and approved the manuscript.

\section{Acknowledgments}

We thank the DNA Sequencing and Genomics Laboratory at the Institute of Biotechnology, University of Helsinki for the Nanostring analyses. Annabrita Schoonenberg (FIMM) is thanked for performing the mIHC stainings. We thank the Digital and Molecular Pathology Unit supported by Helsinki University and Biocenter Finland. Anne Aarnio and Marika Tuukkanen are acknowledged for technical assistance.

\section{Funding}

The study was supported by grants from the Academy of Finland (to SL), Finnish Cancer Foundation (to SL, SM), Juselius Foundation (to SL, SM), University of Helsinki (to SL, $S M)$, and Helsinki University Hospital (to SL, SM).

\section{References}

1. Coiffier B, Lepage E, Briere J, et al. CHOP chemotherapy plus rituximab compared with $\mathrm{CHOP}$ alone in elderly patients with diffuse large-B-cell lymphoma. N Engl J Med. 2002;346(4):235-242.

2. Pfreundschuh M, Trumper L, Osterborg A, et al. CHOP-like chemotherapy plus rituximab versus CHOP-like chemotherapy alone in young patients with good-prognosis diffuse large-B-cell lymphoma: a randomised controlled trial by the MabThera International Trial (MInT) Group. Lancet Oncol. 2006;7(5):379-391.

3. Alizadeh AA, Eisen MB, Davis RE, et al. Distinct types of diffuse large B-cell lymphoma identified by gene expression profiling. Nature. 2000;403(6769):503-511.

4. Rosenwald A, Wright G, Chan WC, et al. The use of molecular profiling to predict survival after chemotherapy for diffuse large-Bcell lymphoma. N Engl J Med.
2002;346(25):1937-1947.

5. Lenz G, Wright G, Dave SS, et al. Stromal gene signatures in large-B-cell lymphomas. N Engl J Med. 2008;359(22):2313-2323.

6. Reddy A, Zhang J, Davis NS, et al. Genetic and functional drivers of diffuse large B-cell lymphoma. Cell. 2017;171(2):481-494.e415.

7. Schmitz R, Wright GW, Huang DW, et al. Genetics and pathogenesis of diffuse large Bcell lymphoma. N Engl J Med. 2018;378(15):1396-1407.

8. Chapuy B, Stewart C, Dunford AJ, et al. Molecular subtypes of diffuse large B cell lymphoma are associated with distinct pathogenic mechanisms and outcomes. Nat Med. 2018;24(5):679-690

9. Scott DW, Gascoyne RD. The tumour microenvironment in B cell lymphomas. Nat Rev Cancer. 2014;14(8):517-534.

10. Nicholas NS, Apollonio B, Ramsay AG. Tumor microenvironment (TME)-driven immune suppression in B cell malignancy. Biochim Biophys Acta. 2016;1863(3):471482.
11. Fridman WH, Pages F, Sautes-Fridman C, Galon J. The immune contexture in human tumours: impact on clinical outcome. Nat Rev Cancer. 2012;12(4):298-306.

12. Keane C, Gill D, Vari F, Cross D, Griffiths L, Gandhi M. CD4(+) tumor infiltrating lymphocytes are prognostic and independent of R-IPI in patients with DLBCL receiving $R$ CHOP chemo-immunotherapy. Am J Hematol. 2013;88(4):273-276.

13. Keane C, Vari F, Hertzberg M, et al. Ratios of T-cell immune effectors and checkpoint molecules as prognostic biomarkers in diffuse large B-cell lymphoma: a populationbased study. Lancet Haematol. 2015; 2(10):e445-455

14. Xu-Monette ZY, Xiao M, Au Q, et al. Immune profiling and quantitative analysis decipher the clinical role of immune-checkpoint expression in the tumor immune microenvironment of DLBCL. Cancer Immunol Res. 2019;7(4):644-657.

15. Wherry EJ, Kurachi M. Molecular and cellular insights into T cell exhaustion. Nat Rev 
Immunol. 2015;15(8):486-499.

16. Booman M, Douwes J, Glas AM, et al. Mechanisms and effects of loss of human leukocyte antigen class II expression in immune-privileged site-associated B-cell lymphoma. Clin Cancer Res. 2006;12(9): 2698-2705

17. Challa-Malladi M, Lieu YK, Califano O, et al. Combined genetic inactivation of beta2Microglobulin and CD58 reveals frequent escape from immune recognition in diffuse large B cell lymphoma. Cancer Cell. 2011;20 (6):728-740.

18. Nijland M, Veenstra RN, Visser L, et al. HLA dependent immune escape mechanisms in B-cell lymphomas: Implications for immune checkpoint inhibitor therapy? Oncoimmunology. 2017;6(4):e1295202.

19. Riemersma SA, Jordanova ES, Schop RF, et al. Extensive genetic alterations of the HLA region, including homozygous deletions of HLA class II genes in B-cell lymphomas arising in immune-privileged sites. Blood. 2000;96(10):3569-3577.

20. Rimsza LM, Roberts RA, Miller TP, et al. Loss of MHC class II gene and protein expression in diffuse large B-cell lymphoma is related to decreased tumor immunosurveillance and poor patient survival regardless of other prognostic factors: a follow-up study from the Leukemia and Lymphoma Molecular Profiling Project. Blood. 2004:103(11):4251-4258

21. Holte H, Leppa S, Bjorkholm M, et al. Dosedensified chemoimmunotherapy followed by systemic central nervous system prophylaxis for younger high-risk diffuse large Bcell/follicular grade 3 lymphoma patients: results of a phase II Nordic Lymphoma Group study. Ann Oncol. 2013;24(5):13851392.

22. Leppa S, Joergensen J, Tierens A, et al. Dosedense chemoimmunotherapy including early CNS prophylaxis for high-risk DLBCL. Final analysis from a Nordic Phase II study (the CHIC trial). Blood. 2016;128(22):1854.

23. Leivonen SK, Pollari M, Bruck O, et al. T-cell inflamed tumor microenvironment predicts favorable prognosis in primary testicular lymphoma. Haematologica. 2019;104(2): 338-346.

24. Vandesompele J, De Preter K, Pattyn F, et al. Accurate normalization of real-time quantitative RT-PCR data by geometric averaging of multiple internal control genes. Genome Biol. 2002;3(7):Research0034.

25. Carpenter AE, Jones TR, Lamprecht MR, et al. CellProfiler: image analysis software for identifying and quantifying cell phenotypes. Genome Biol. 2006;7(10):R100.

26. Hans CP, Weisenburger DD, Greiner TC, et al. Confirmation of the molecular classification of diffuse large B-cell lymphoma by immunohistochemistry using a tissue microarray. Blood. 2004;103(1):275-282.
27. Newman AM, Steen CB, Liu CL, et al Determining cell type abundance and expression from bulk tissues with digital cytometry. Nat Biotechnol. 2019;37(7):773782.

28. Monti S, Savage KJ, Kutok JL, et al. Molecular profiling of diffuse large B-cell lymphoma identifies robust subtypes including one characterized by host inflammatory response. Blood. 2005;105(5):18511861

29. Dysvik B, Jonassen I. J-Express: exploring gene expression data using Java. Bioinformatics. 2001;17(4):369-370.

30. Xu-Monette ZY, Zhou J, Young KH. PD-1 expression and clinical PD-1 blockade in Bcell lymphomas. Blood. 2018;131(1):68-83.

31. Josefsson SE, Beiske K, Blaker YN, et al. TIGIT and PD-1 mark intratumoral T cells with reduced effector function in B-cell nonHodgkin lymphoma. Cancer Immunol Res. 2019;7(3):355-362.

32. Chen BJ, Dashnamoorthy R, Galera P, et al The immune checkpoint molecules PD-1, PD-L1, TIM-3 and LAG-3 in diffuse large Bcell lymphoma. Oncotarget. 2019; 10(21):2030-2040.

33. Xiong H, Mittman S, Rodriguez R, et al. Coexpression of inhibitory receptors enriches for activated and functional CD8(+) I cells in murine syngeneic tumor models. Cancer Immunol Res. 2019;7(6):963-976.

34. Lesokhin AM, Ansell SM, Armand P, et al. Nivolumab in patients with relapsed or refractory hematologic malignancy: preliminary results of a Phase Ib study. J Clin Oncol. 2016;34(23):2698-2704

35. Ansell SM, Hurvitz SA, Koenig PA, et al Phase I study of ipilimumab, an anti-CTLA4 monoclonal antibody, in patients with relapsed and refractory B-cell non-Hodgkin lymphoma. Clin Cancer Res. 2009; 15(20):6446-6453.

36. Ansell SM, Minnema MC, Johnson P, et al. Nivolumab for relapsed/refractory diffuse large B-cell lymphoma in patients ineligible for or having failed autologous transplantation: a single-arm, Phase II study. J Clin Oncol. 2019;37(6):481-489.

37. Sakuishi K, Apetoh L, Sullivan JM, Blazar BR, Kuchroo VK, Anderson AC. Targeting Tim-3 and PD-1 pathways to reverse T cell exhaustion and restore anti-tumor immunity. J Exp Med. 2010;207(10):2187-2194.

38. Koyama S, Akbay EA, Li YY, et al. Adaptive resistance to therapeutic PD-1 blockade is associated with upregulation of alternative immune checkpoints. Nat Commun. 2016;7:10501

39. Fourcade J, Sun Z, Benallaoua M, et al. Upregulation of Tim-3 and PD-1 expression is associated with tumor antigen-specific CD8+ $\mathrm{T}$ cell dysfunction in melanoma patients. J Exp Med. 2010;207(10):2175 2186
40. Zhou Q, Munger ME, Veenstra RG, et al. Coexpression of Tim-3 and PD-1 identifies a CD8+ T-cell exhaustion phenotype in mice with disseminated acute myelogenous leukemia. Blood. 2011;117(17):4501-4510.

41. Hill BT, Roberts ZJ, Rossi JM, Smith MR. Marked re-expansion of chimeric antigen receptor (CAR) T cells and tumor regression following nivolumab treatment in a patient treated with axicabtagene ciloleucel (axi-cel; KTE-C19) for refractory diffuse large B cell lymphoma (DLBCL). Blood. 2017;130(Suppl 1):2825.

42. Filion LG, Izaguirre CA, Garber GE, Huebsh L, Aye MT. Detection of surface and cytoplasmic CD4 on blood monocytes from normal and HIV-1 infected individuals. Immunol Methods. 1990;135(1-2):59-69.

43. O'Doherty U, Steinman RM, Peng M, et al. Dendritic cells freshly isolated from human blood express CD4 and mature into typical immunostimulatory dendritic cells after culture in monocyte-conditioned medium. Exp Med. 1993;178(3):1067-1076.

44. Valentin A, Rosati M, Patenaude DJ, et al. Persistent HIV-1 infection of natural killer cells in patients receiving highly active antiretroviral therapy. Proc Natl Acad Sci U S A. 2002;99(10):7015-7020.

45. Alvaro T, Lejeune M, Salvado MT, et al. Outcome in Hodgkin's lymphoma can be predicted from the presence of accompanying cytotoxic and regulatory $\mathrm{T}$ cells. Clin Cancer Res. 2005;11(4):1467-1473.

46. Koreishi AF, Saenz AJ, Persky DO, et al. The role of cytotoxic and regulatory $\mathrm{T}$ cells in relapsed/refractory Hodgkin lymphoma. Appl Immunohistochem Mol Morphol. 2010;18(3):206-211.

47. Oudejans JJ, Jiwa NM, Kummer JA, et al. Activated cytotoxic $\mathrm{T}$ cells as prognostic marker in Hodgkin's disease. Blood. 1997;89(4):1376-1382.

48. Muris JJ, Meijer CJ, Cillessen SA, et al Prognostic significance of activated cytotoxic T-lymphocytes in primary nodal diffuse large B-cell lymphomas. Leukemia. 2004 18(3):589-596.

49. Zitvogel L, Apetoh L, Ghiringhelli F, Kroemer G. Immunological aspects of cancer chemotherapy. Nat Rev Immunol. 2008;8(1):59-73

50. Carreras J, Lopez-Guillermo A, Fox BC, et al. High numbers of tumor-infiltrating FOXP3positive regulatory $\mathrm{T}$ cells are associated with improved overall survival in follicular lymphoma. Blood. 2006;108(9):2957-2964.

51. Tzankov A, Meier C, Hirschmann P, Went P, Pileri SA, Dirnhofer S. Correlation of high numbers of intratumoral FOXP3 + regulatory $T$ cells with improved survival in germinal center-like diffuse large B-cell lymphoma, follicular lymphoma and classical Hodgkin's lymphoma. Haematologica. 2008;93(2):193200. 